\title{
E-Learning through National Knowledge Network
}

\author{
Vipin Saxena, Pawan Kumar Chaurasia, and Nimesh Mishra
}

\begin{abstract}
Due rapid growth in the field of Computer Networking, Government of India has set up a Nationwide Network called as National Knowledge Network (NKN) with objective to enhance the quality of higher education teaching and research and to promote e-Learning across the Indian Universities/Institutions/Research Labs, etc. The present paper describes e-Learning method on National Knowledge Network and how to access the information through NKN \& role of Information Library Network (INFLIBNET) on NKN are described. The paper also consists of details about the Virtual Classes through this network.
\end{abstract}

Index Terms-National knowledge network (NKN), eLearning, INFLIBNET, virtual class \& virtual university.

\section{INTRODUCTION}

E-Learning or electronic learning in the developing country like India is gaining popularity very slowly-slowly while in the developed country like Singapore or Malaysia, e-Learning has set up a new dimension of learning. More than half of the population of India today is below 25 years of age and the numbers of Internet users are growing continuously, therefore, there are tremendous scopes of enhancing the quality of online education in India. With this objective, Government has setup a Nationwide Network called as National Knowledge Network with a high bandwidth 1 Gbps which can be extended up to $10 \mathrm{Gbps}$ in near future. E-Learning is increasingly being used in commercial organization to improve efficiency and reduce costs. In India, students are interested to do Online certification/course along with the full time traditional course for enhancing their skills. Therefore, online education in India is very convenient to young students and day by day the enrollments for online education are increasing. Mostly reputed Institutes like Indian Institute of Technology, Indian Institute of Management and other Foreign Universities offer e-Learning courses.

E-Learning is the use of technology to enable people to learn anytime and anywhere. People can learn in many different ways and at different times. There are different ways of e-learning: asynchronous and synchronous. In asynchronous there are two types of method self-paced courses and discussion groups. In synchronous there are various types of e-learning method, some of them are Virtual Class room, Audio and Video Class Room, Chat, Application Sharing and Instant Messaging.

E-Learning is used in every field of the creativity work

Manuscript received March11, 2011; revised July 6, 2011.

Vipin Saxena is with the Department of Computer Science, Babasaheb Bhimrao Ambedkar University (A Central University) Lucknow (U.P), India, 226025(vsax1@rediffmail.com).

Pawan Kumar Chaurasia is with the Department of Information Technology Babasaheb Bhimrao Ambedkar University (A Central University) Lucknow (U.P), India, 226025(pkc.gkp@gmail.com\&).

Nimesh Mishra is with the Department of Computer Science, Babasaheb Bhimrao Ambedkar University (A Central University) Lucknow (U.P), India, 226025(misra.nh@gmail.com). and the resources are maximum utilized by the people in different area. Gloria [1] surveyed on the students of the distance learning Institute (DLI) of the Universities and found that the students preferred a combination of teaching for effective learning. Zhang and Hong [2] described a method for Research on Computer Technology for eLearning in Higher Education. Yang and Luo [3] surveyed in a China and presented a report of China Internet Network Information Centre (CNNIC) in 2009 and found the facts that e-Learning has developed the new ideas and it also enhance the psychological growth of the student. They also discussed about the computer technology as a teaching tool for e-learning for the college students in higher education. In [4], authors discussed the emotional education based on the virtual reality in e-Learning and design the architecture model, network model.

In recent years, digital technology is widely used in area of distance education. Distance education covers a wide area of people of different segments of the population. Digital technology is the developing trend of information. This concept is analyzed in [5] and authors discussed the digital technology for e-Learning in distance education [5]. In [6], Michael \& Neco introduced about the e-Learning Virtual classrooms and evaluates a whiteboard application over and IMS test-bed. Virtual classrooms have become more common with the introduction of Web 2.0 providing another platform on which students can engage academically. In [7], authors introduced e-Learning approach based on community detection. With this approach users belong to the same community can share the proper learning contents easily. E-Learning system will get higher efficiency by introducing right learning contents to right users at right time. Nillson et al. also introduced Semantic Web Technology has been applied into e-Learning system [8]. Some authors have recognized the importance of communication in the e-Learning process [9]. In [10], authors focused on the work of South Africa government to design a National Information Society programme which will improve the standard of the citizen with the help of Information and communication technology. Currently virtual reality is also applied in education fields. There are many development platforms where one can see the virtual imagination like Second Life [11], active worlds [12][13], etc.

In the present work a brief description about the National Knowledge Network is given whose purpose is to connect all the Universities/Institutions/Research Labs belonging to the private or public sectors. The network is having the high speed Internet facility currently up to $1 \mathrm{Gbps}$ and can also be extended up to $10 \mathrm{Gbps}$ in near future. The second part of paper describes the accessing of the information i.e. econtents on this network and types of services are looking after by INFLIBNET, Ahmedabad [14]. A method for eLearning through Virtual Classes is also described in the end of the paper. 


\section{NATIONAL KNOWLEDGE NETWORK}

Ministry of Communication and Information Technology, Government of India is fully responsible for implementing and review of National policies in the field of Information Technology from time to time. In the year 2009, Government has established the National Knowledge Network with multiple gigabyte bandwidths to connect Knowledge Institutions across the country. The main objective is to enhance the Internet quality, e-commerce and Information Technology education and development of electronics media to access and overall to enhance the quality of teaching and research. A sample diagram with services under NKN is shown in the Fig. 1.

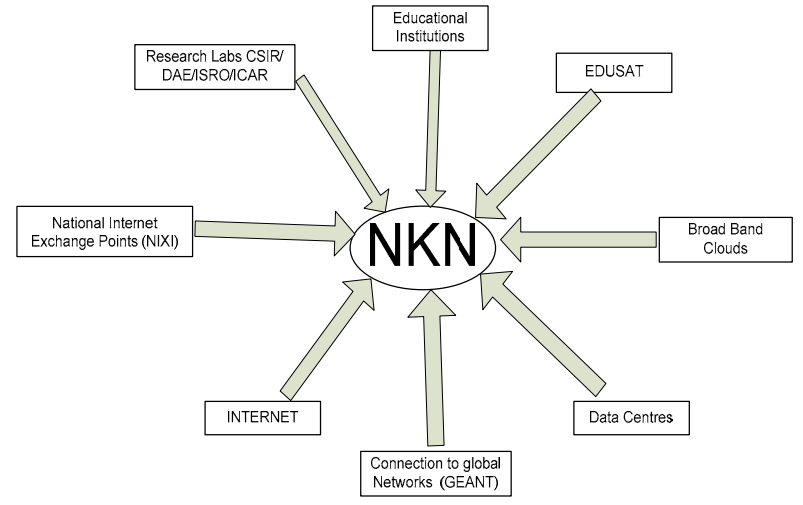

Fig.1. Services Provided by NKN

This project is under phase 1 and around 95 Indian Institutions/Universities/ Research Labs have successfully connected on this network and around 234 Institutions/Universities/Research Labs will get connectivity very soon. The faster Internet services are provided by NKN with 1 Gbps bandwidth and on this network one can download and transfer the e-contents within a fraction of seconds. Since e-contents are very interactive because of a lots of multimedia and animation, therefore there is need of such kind of Network. In this network, the other kinds of services have already been started like to share the classes and initially this has been started in IIT's and IIM's but could not get connectivity to the rest of the Universities/Institutions and in future, all the virtual classes have to be connected through this network. The INFLIBNET services have also been started on this network for accessing the e-Journals, Digital Notes, etc. and more than 10,000 Journals are available through NKN. The other services provided by the NKN are collection of vast data i.e. Data Centres, sharing of the computer labs for fast and reliable computing of the research problems and also sharing of the medicals labs i.e. telemedicine, pathological labs, etc.

In some of the Universities, virtual classes have already been started by the use of NKN. They are using the electronic devices like Digital Video Recorder, Multimedia Computer System alongwith the Projector, Zoom Movable Camera, Focus Lighting etc. and viewer can view the class room by using the freeware softwares like Netviewer as shown below in the Fig. 2 and through this software user can view the virtual class on Local Area Network or Internet by entering IP no. say 192.168.10.20 and entering the option Local Area Network (LAN) or Internet.

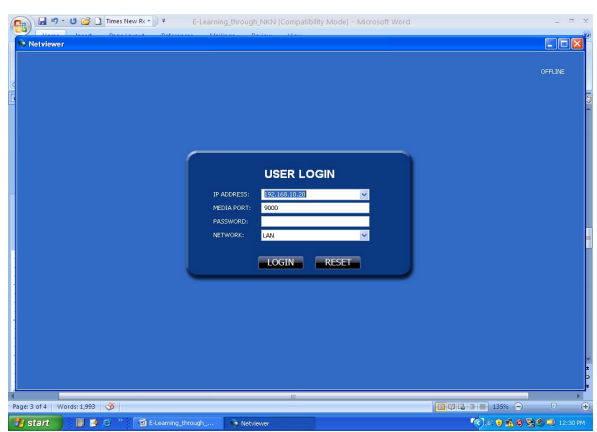

Fig. 2. Virtual Class Login Through Netviewer

\section{ACCESSING CONTENTS ThROUGHINFLIBNET ON NKN}

INFLIBNET plays a vital role in the collection, development and dissemination of scientific and technical information to meet the present and future needs of the centre. Library is a fully computerized by using SOUL software. Library maintains database of participants who attended various training programmes at INFLIBNET Centre. INFLIBNET provides Reference, Document Delivery, Current Awareness, Inter Library Loan, Electronic Information Services, etc.

To search the record from INFLIBNET, it is categorized into three parts: Basic Search, Free-Test Search and Boolean Search. In Basic Search first we have to select the various options from the search record, and then input the title of the record, click on the search. Second method is input title, author name or subject heading in the search box. Last method is the combination of above methods i.e BOOLEAN search.

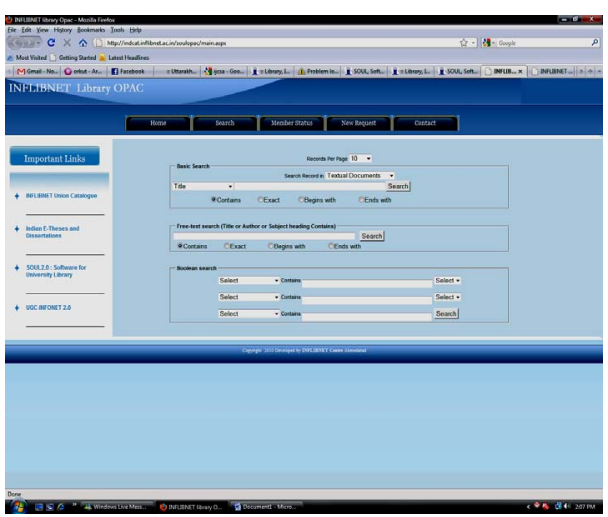

Fig.2. Search Methods from INFLIBNET

These types of services are available on the National Knowledge Network so that user can download the e- Books \& Journals, e- Thesis, magazines, Digital Notes, etc. within a fraction of seconds.

\section{CONCLUDING REMARKS}

Form the above it is concluded that NKN is a powerful network which provides various kinds of fast services like High Speed Internet, accessing of the Virtual Class, Digital Books \& Journals, digital information, storage of data's in the form of data centres, etc. The method for searching the e-books \& journals through INFLIBNET is given and also how to access the Virtual Classes on LAN/INTERNET is explained in the paper. This work can be extended for the mining of the data on NKN network as it is much faster in 
comparisons of the other networks.

\section{ACKNOWLEDGMENTS}

The authors are very thankful to Prof. B. Hanumaiah, Vice-Chancellor, Babasaheb Bhimrao Ambedkar University ( A Central University), Vidya Vihar, Rae Bareli Road, Lucknow, India for providing excellent computation facilities in the University campus. Thanks are also due to University Grant Commission, New Delhi for providing research funding to the University.

\section{REFERENCES}

[1] Gloria C. Alaneme, Peter O. Olayiwola, Comfort O. Reju, "Combining Traditional Learning and the E-Learning Methods in Higher Distance Education: Assessing Learners Preference", $4^{\text {th }}$ International conference on distance Learning and education (ICDLE) 2010 pg 187-190.

[2] Ning Zhang, Hong Bao, "Research on Computer Technology for ELearning in Higher Education", International Conference on EEducation, E-Business, E-Management and E-Learning 2010, pg295-298.

[3] Yang Jiong, Luo Ting, "E-Learning in Uvniversity: a social psychology perspective", International conference on E-Business and E-Government 2010, pg 5144-5147.

[4] Huiquin Zhao, Bo Sun, Xiaoyan Hu, Xiaoming Zhu " The Study of Emotional Education Based on Virtual Reality in E-Learning", Ist International Conference on Information science and Engineering (ICISE2009), pg 3540-3543.

[5] Ning Zhang, Hong Bao, " Research on E-Learning with Digital Technology in Distance Education", International Conference on EEducation,E-Business, E-Management and E-Learning 2010, pg299-302.

[6] Michael Nyarko, Neco Ventura, "E-Learning: Virtual Classrooms as an Added Learning Platform", IEEE regions8 SIBIRCON-2010, July $11-15,2010 \mathrm{pg} 426-431$.

[7] Lianhong Ding, Peng Shi,"Introducning E-Learning Based on Community Detection", first Workshop on Educational Technology and computer science in 2009 , pg 824-827.
[8] M. Nilsson, M. Palmér and A. Naeve, "Semantic Web Meta-data for e-Learning-Some Architectural Guidelines", Proc. 11th World Wide Web Conference, Hawaii, USA, 2002.

[9] N. Augar, R. Raitman and W. Zhou, "From e-Learning to Virtual Learning Community: Bridging the Gap", Proc. ICWL2004, LNCS3143, 2004, pp. 301-308.

[10] S.Dunn, "The virtualization of education," the Futurist. 2000.34(2):pp.34-38.

[11] http://www.secondlife.com (Accessed on 12 Feb 2011)

[12] http://www.activeworlds.com (Accessed on $12 \mathrm{Feb} .2011$ ).

[13] http://wiki.activeworlds.com(Accessed on 30 Jan. 2011).

[14] www.inflibnet.ac.in (Accessed on 23 Feb. 2011).

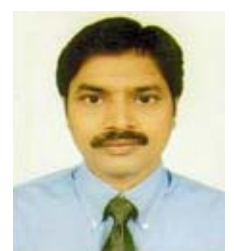

Vipin Saxena is an associate professor, founder and ex-head, Department of Computer Science, Babasaheb Bhimrao Ambedkar University, Lucknow, India. He got his M.Phil. Degree in Computer Application in 1992 \& Ph.D. Degree work on Scientific Computing from University of Roorkee (renamed as Indian Institute of Technology, Roorkee, India) in 1997 . He has more than 15 years of

teaching experience and 18 years research experience in the field of Scientific Computing \& Software Engineering He has published more than Eighty International and National research papers and authored four books on Computer Science. Phone: +91-9452372550, Fax: +91-522-2440821, Email:vsax1@rediffmail.com

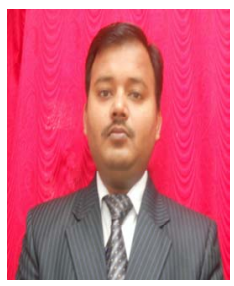

Pawan Kumar Chaurasia is an assistant professor with the Department of Information Technology, Babasaheb Bhimrao Ambedkar University, (A Central University), Raebareli Road, Lucknow, India. Currently he is producing the research papers on the various software designs through UML Modeling. He is a member of Computer Society of India, Mumbai, and very recently received best research paper prize from Amity University, Lucknow, India. 